\title{
Learning to work Interculturally and Virtually: developing postgraduate hospitality management students across international HE institutions
}

\author{
Judith M Gannon, Zaida Rodrigo, Ricard Santomà
}

\begin{abstract}
Given the challenges of developing inter-culturally competent, digitally literate, team players amidst a realm of other postgraduate competencies this paper outlines the initiative developed by academic teams from three European institutions. The paper outlines the virtual intercultural collaboration and its development and then reports on the results of a survey conducted with participating students from two years of the initiative. Students' perceptions of the generic value of specific skills sets in virtual team working and intercultural competence are identified as well as their views of the specific project's capacity to develop their own skills in the relevant areas, are explored. The results suggest that since social media, team work and intercultural interactions seem to be ever present dimensions of the contemporary world of work it appears to be important that students encounter meaningful virtual and intercultural learning opportunities during their postgraduate management studies. Finally this paper highlights the value of inter-programme teaching and learning collaborative activities between European higher education institutions.
\end{abstract}

\section{Introduction}

Since the Bologna Declaration of June 1999 European higher education institutions have attempted to move forward with the synchronisation of $\mathrm{HE}$ qualification systems in Europe. The joint recognition of degree qualifications, credit accumulation and transfer and the facilitation of European mobility for staff and students have been part of these developments. Further declarations of intent for convergence at this level of education have maintained the change momentum for Universities and faculty while they also vie for student numbers and research money (Keeling, 2006; Newman, Couturier \& Scurry, 2010). Alongside these events there has been a growing requirement to provide students with the skills and knowledge that leads to competent professionals for the international hospitality and tourism sectors (Gannon, 2008; Tavitiyaman, Weerakit \& Ryan, 2014). These sectors have been marked by a vocational legacy and their own nature has always been characterised by a diverse, mobile workforce (Duncan, Scott \& Baum, 2013). This increasing diversity poses new challenges in the hospitality management education, in particular at postgraduate level as these students are the new professionals shaping the future of the industry and, hence, require interpersonal competences to lead such workforces and manage complex international organisations effectively.

Among the different pedagogical approaches, experiential learning proves to be an effective route in this area of education where theory and practice can be linked implicitly and explicitly.

At the same time, there is growing interest in virtual team working for professionals as technology facilitates synchronous and asynchronous communication and companies expand across national borders through networks, mergers and acquisitions, and organic growth mechanisms (Matveev \& Milter, 2004; Hertel, Geister \& Kontradt, 2005). This phenomenon of growth has been particularly apparent in the international hospitality and tourism industry where networks and complex distribution channels and supply chains are particularly evident (Xiao, O'Neill \& Mattila, 2012). The management education literature has also highlighted the value of developing prospective managers' and leaders' digital, virtual working and intercultural skills but bemoaned the difficulties of providing suitable meaningful experiences in academic settings to advance these skills (Richards \& Bilgin, 2012; Erez et al., 2013). 
Whereas student diversity in the classroom has the potential to enrich education, this diversity also has the potential to create conflict as people come together with different values and ways of understanding (De Vita, 2001; 2002; Blasco, 2009; Patterson, Carrillo \& Salinas, 2012). There is an increasing need to be aware of cultural differences, as assimilating these is paramount in determining the effective management of businesses reinforcing the need to develop cross-culturally aware managers (Taras et al., 2013). To achieve this aim of culturally competent managers universities, in particular, are challenged to bring students closer to industry by linking theory and practice in the curricula through simulation activities and virtual interactions. This article outlines a virtual intercultural team working initiative across three European higher education institutions and its development and evaluation of the results of a survey conducted with participating students. Students' perceptions of the generic value of specific skills sets in virtual team working and intercultural competence are reported as well as their views of the specific initiative's capacity to develop knowledge and skills in the relevant areas. The results suggest that since social media, team work and intercultural interactions seem to be ever present dimensions of the contemporary world of work it appears to be important that students encounter meaningful simulated virtual and intercultural learning opportunities during their studies. This highlights the value of inter-programme teaching and learning collaboration activities. Furthermore while students tend to be familiar with social media they do not use it as an effective working medium and the ability to communicate purposively across cultures to achieve an assignment brief enhance their digital and information literacy skills further. As such this paper explores a unique teaching and learning initiative, which connects postgraduate students in different countries and simulates a virtual intercultural team working environment and task.

\section{Literature Review}

\subsection{Experiential Learning}

A variety of pressures have reinforced the role of student employability on the agendas of business schools (Avramenko, 2011) as long term career prospects and graduate competencies are directly linked with the students' reasons to study. Experiential learning is of growing interest in higher education as it carries the student closer to an area of knowledge as well as facilitating deep knowledge (Ruhanan, 2005). Bringing students closer to the world of work through the linking theory and practice in the curricula is gaining greater importance with simulation activities and virtual interactions proving to be useful tools in higher education settings (Tiwari et al., 2014, Ruhanen, 2005). "Learning in such a way is more effective even than learning within the real work environment or "on the job", as the latter, while providing direct experience, is limited by the routine nature of tasks and the complexity of the work environment" (Avramenko, 2011, p. 356). This type of experiential learning promotes new competencies related to industry knowledge and understanding (Lee, 2008) and proves effective as students have higher levels of enthusiasm towards the learning approach, leading to increased knowledge retention and skill acquisition (Ruhanen 2005).

Experiential learning explores learning by doing and reflecting. This type of learning is beneficial for deep learning and allows students to better assimilate knowledge and its future application as future managers (Edelheim \& Ueda, 2007; Tiwari et al, 2014). Experiential learning is based on the perspective that learning is a holistic process that incorporates all our life experiences and, indeed, to learn, people should engage in higher order thinking to personalise information (Edelheim \& Ueda, 2007; Finch et. al. 2015). Communication of the experiences associated with experiential learning form a crucial part of this approach (Baker, Jensena \& Kolb, 2002) which means that learning in preparation for diverse and dispersed environments should form a core part of experiential learning. Experiential learning is also seen to be at the root of lifelong learning (Kolb and Kolb, 2005) as it is often conceived as a process of learning from direct life experiences controlled by the individual. Following from this relationship between learning and life experiences, experiential learning as Kolb's research (2005) indicates should balance the academic input and life experience. 
Huddleston and Unwin (2007) believed that a great deal of higher education teaching fails to recognise the importance of these experiences. Consistent with constructivist learning theory (Vygotsky, 1978) involving students in a number of processes that actively encourage them to move through the experiential learning cycle and value previous experiences and knowledge is crucial. In an attempt to emphasise the value of experiential learning, students in this study participated in practical workshops in addition to classroom-based sessions linked to the same theoretical areas as the workshop sessions. As part of these learning aspects, Maier and Thomas (2013) affirm that students in vocational/professional areas, such as hospitality, engage in experiential learning activities to achieve higher perceptions of learning outcomes and gain more competencies relevant for industry job placement and expected performance (Lee, 2008).

\subsection{Cross-cultural management in education}

Postgraduate management education is becoming more diverse, with students from different backgrounds providing new viewpoints to mirror current corporate arrangements where people are working with diversity on a regular basis (Warwick, 2014). As affirmed by Bigelow et al. (2015 p. 48) "Management classrooms are becoming increasingly diverse as they attract students from around the world. This diversity has the potential to enrich classrooms but also has the potential to create conflict as people come together with different life experiences and with differing assumptions about ethical issues, interpersonal interactions, organizational processes, and the role of organizations in society." Within the field of international hospitality and tourism management, educators have recognised the need for intercultural skills development amidst cross-cultural experiences, though developing suitable and realistic teaching and learning interventions has remained a challenge (Gannon, 2008; Tavitiyaman et al., 2014).

To manage culturally diverse groups effectively it is important to bridge the gap between different points of view. Here, tacit and explicit knowledge plays an important role as Analoui, Sambrook \& Doloriert (2014) state that tacit knowledge is highly personal, hard to formalise and difficult to share with others, whereas explicit knowledge is formal and systematic. To share cognitive and technical tacit knowledge elements of collaboration with other students is beneficial as the participants show their beliefs and the way groups should operate, and more so in multicultural backgrounds as it helps towards a better understanding of similarities and differences amongst participants (Analoui et al., 2014). Cross-cultural management focuses on practice-oriented areas in management and this affects the curricula and teaching of these modules as they are aimed at imparting knowledge and skills that can be applied in practice. Over recent decades cross-cultural competencies have become a feature of management education with Joy and Poonamallee (2013 p. 396) arguing that the field has reached a crossroads and "Any manager today, not just expats, will find that they are part of a globalised workplace and cannot be effective without a culturally grounded understanding of management." However, researchers have identified that there are challenges associated with ensuring students from different cultural backgrounds learn effectively together. For example De Vita $(2001 ; 2002)$ highlighted the challenges of managing home and international students' expectations and perceptions of the value and fairness of multicultural teaching, learning and assessment experiences. More recently Cotton, George \& Joyner (2013) have explored intercultural interactions in group work and concerns over participation by gender and cultural group Recommendations for ameliorating issues of expectations, perceptions and participations include careful classroom management, the assignment of specific roles in multicultural group work and assessment based upon the process of the group collaboration rather than purely the final product of assessment (presentation, report or website) (Cotton, et al., 2013).

Even though the practical situations are usually part of the curricula, educators cannot teach only about the cross-cultural differences and stereotypes. Instead, Egan and Bendick (2008, p. 387) suggest "educators must equip students to understand how cultural differences work and thus to turn cultural competence into a cultural advantage". Training in cultural competence teaches students to analyse individuals as unique, complex combinations of influences and moves beyond national stereotyping and clichés. Besides, cultural competence, there is also the need to enhance cultural intelligence which focuses upon the cognitive, the motivational and body language aspects to "tease out a person's or group's behaviour whose features would be true of all people and all groups. ( $p$. 391.) Cultural intelligence provides therefore, a sense of belongingness to, and identification with the global work context (Egan \& Bendick, 2008). These arguments highlight the benefits of moving away 
from a traditional classroom lecture environment, in line with the contention $t$ that managers cannot be created in such an environment and instead there is a requirement to expose students to experiential learning situations where they can gain first hand experiences (Mintzberg \& Gosling, 2002).

\subsection{Cross-cultural Experiential Learning}

The value of an experiential-learning approach in management education, in general, has been explained theoretically (Kolb and Kolb, 2005) and demonstrated empirically (Taras et.al., 2013) indicating that cultural differences are paramount in shaping the operations and management of business, and reinforcing the necessity to develop cross-culturally aware managers. Matveev and Nelson (2004) support this by indicating how cross-cultural training can focus on fostering mutual interest and appreciation of differences, to work better in collaborations and therefore minimise any potential negative aspects in a multicultural corporate culture.

As there is a growing need to involve and expose students to different cross-cultural situations and challenges, the growth in internet-based communications become useful to enable experimentation in situations where cross-cultural challenges and time zones are different (Taras et al., 2013). Moreover, this new computerised or virtual way of working is also closely linked to contemporary business scenarios where it is now common to work in virtual teams and the means of communication is internet based (Au \& Marks, 2012; De Jong, Schalk \& Curseu, 2008; Morris, 2008). Indeed the continued growth of international business and the technological advances which have emerged in recent years have accelerated further the adoption of virtual working environments, with colleagues and team members no longer co-present (Pangil \& Chan, 2014; Au \& Marks, 2012). Erez et. al (2013), highlight how internet-based communication enables organisations to globalise and benefit from their culturally diverse and geographically dispersed workforces. Moreover, they explain how "experiential learning theory, creates opportunities for cycles of personal experience, reflection and readjustment, enabling individuals to actively construct their knowledge, thoughts, and feelings". Taras et al. (2013) also state that there has been an increase of virtual collaboration in the corporate world, which, in a classroom environment, has been adopted as distance learning and the virtual generation.

Following the same lines Lipnack and Stamps (2000) recommend virtual collaboration initiatives as an effective way to develop the students' competencies in cross-cultural management situations as the students are forced to work with different cultures and time zones. Such initiatives also present opportunities to enhance their digital literacy skills and encounter and reflect upon the challenges of team work for those who are not co-present (Richards \& Bilgin, 2012). For this reason, it is argued that virtual teams are becoming a unique learning tool as affirmed by Pless, Maak and Sthal, (2011 p.498) "One identified way to create such transformative encounters is the deep immersion exercise, which has been shown to have significant impact on developing individuals' intercultural competence."

Opportunities for international management education programmes to promote hands- on experiences in working in virtual multicultural team settings (Taras et al, 2013; Richards \& Bilgin, 2012; Erez et al., 2013) are therefore widely recommended. Mendenhall et al., (2013 p. 442) contend that "students must consciously analyse and examine their assumptions and thought patterns so that a discernible increase in their cross-cultural competencies and skills is achieved. Providing students with a framework by which they can accomplish this, within the context of a traditional classroom, is the challenge that must be met if we are to matriculate students who possess cross-cultural competences that are associated with global managerial effectiveness". Indeed where companies expand across national borders through networks, mergers and acquisitions as well as organic growth mechanisms (Matveev \& Milter, 2004; Hertel et al., 2005) and technology enables synchronous and asynchronous communication there is a need to involve, expose and equip students for these different cross- cultural situations and challenges (Avramenko, 2012). 
While studies on the use of multicultural teams in HEls are extensive (Analoui et al., 2014; Cotton et al., 2013) and there is a growing literature on virtual multicultural teams and groups (Taras et al., 2013; Richard \& Bilgin, 2012) at University level pedagogy there remains limited evidence of evidence from teaching and learning approaches using virtual multicultural teams operating across institutions and national boundaries (Patterson, Carrillo \& Salinas, 2012; Crossman \& Bordia, 2011). Crossman \& Bordia (2011) used 'wikis' to explore the perceptions of home and international students located in Australia and the Netherlands towards the development of intercultural communication skills. The findings, though solely based on the results from the Australian based students, emphasise the potential conflict associated with cultural differences in developing working (and social) relationships and suggest these were compounded by the use of virtual methods of communication. The authors suggest that acknowledging the 'emotional and social factors involved in learning' need to be tackled alongside the methods of learning themselves (2011 p. 349). Similar to Cotton et al. (2013) they make a case for asking students to reflect upon the ways culture impacts upon communication and collaboration activities offers a better level of insight for participants.

Patterson et al., (2013) report on an initiative where students in the United States collaborated with students in Colombia through a virtual classroom on a social development and geography project. Mixed teams were developed so that students from the different countries could exchange research data on migrant groups in Atlanta and Bogota and co-author a final report on these migrant populations. The study highlights how safe travel recommendations, financial resources, language differences, semester timetables and technology restrictions confronted the Faculty coordinating and delivering the initiative. Overall, however, they argue that 'the virtual classroom was a positive experience for both students and the faculty." and underline how their own institutions' commitment to the initiative as well as the enthusiasm and cooperation of academics were paramount in the delivery of the initiative (Patterson et al., 2013 p.193). Amidst the intent for convergence and collaboration across HEls and the call for student learning experiences which enhance their virtual, intercultural and team working abilities these studies highlight the challenges of developing and delivering such projects.

\section{Overview of simulated virtual intercultural collaboration initiative}

Postgraduate hospitality and tourism management education has flourished in the last two decades due primarily to the growth and evolution of international organisations which demand that their managers and executives demonstrate strategic as well as operational management expertise (Barron, 2014; Hodari \& Sturman, 2014). The three institutions involved in this initiative have collaborated for nearly a decade on a Master's programme in hospitality management, whilst also operating their own postgraduate programmes. Based in The Netherlands, Spain and the UK, one of the recurring features of the programmes operated has been the development of intercultural skills as part of their postgraduate skills profile. The focus of this research is the students on the joint Masters programme operated and delivered in the Netherlands and Spain, which the UK University supports by way of specialist lectures in research methods and intercultural management, and students on the postgraduate programmes operated by the UK institution. The students on the joint Masters programme spend four months in the Netherlands, four months in Spain and four months on internship.

Since 2010 the cross-cultural management modules on the postgraduate programmes in the respective countries have included as a component a simulated virtual team work initiative or virtual intercultural collaboration (VIC). Figure 1 indicates how this initiative operates with students introduced to the partner programmes and institutions and informed about the initiative in two threehour sessions in their respective institutions. During the briefings the students were also introduced to Honey \& Mumfords' (1992) learning style questionnaire and asked to complete this survey to help them consider their learning style preferences. The value of understanding their personal learning styles was also explored in these sessions and students were asked to reflect and share their learning style preferences with their newly allocated virtual (and physically present) team members. This helped emphasise that this was a learning experience rather than solely another way of getting students to meet assessment requirements and also allowed all groups to share a 'common language' of learning during their initial meetings. 
Student teams are allocated by the Faculty coordinators based upon the creation of heterogeneous groups across institutions, nationalities and extent of prior work experience in the hospitality and tourism industry. Typically groups of six to eight students are compiled with members from the different institutions. Initial editions of this initiative were assessed and evaluated independently by each programmes' own quality review systems. However, the faculty teams also undertook focus groups with students following the final team presentations to garner feedback for subsequent versions of the initiative. To provide a more systematic evaluation of this collaborative teaching and learning intervention an online questionnaire was developed.

Figure 1 Outline of Simulated Virtual Intercultural Collaboration (VIC) Initiative

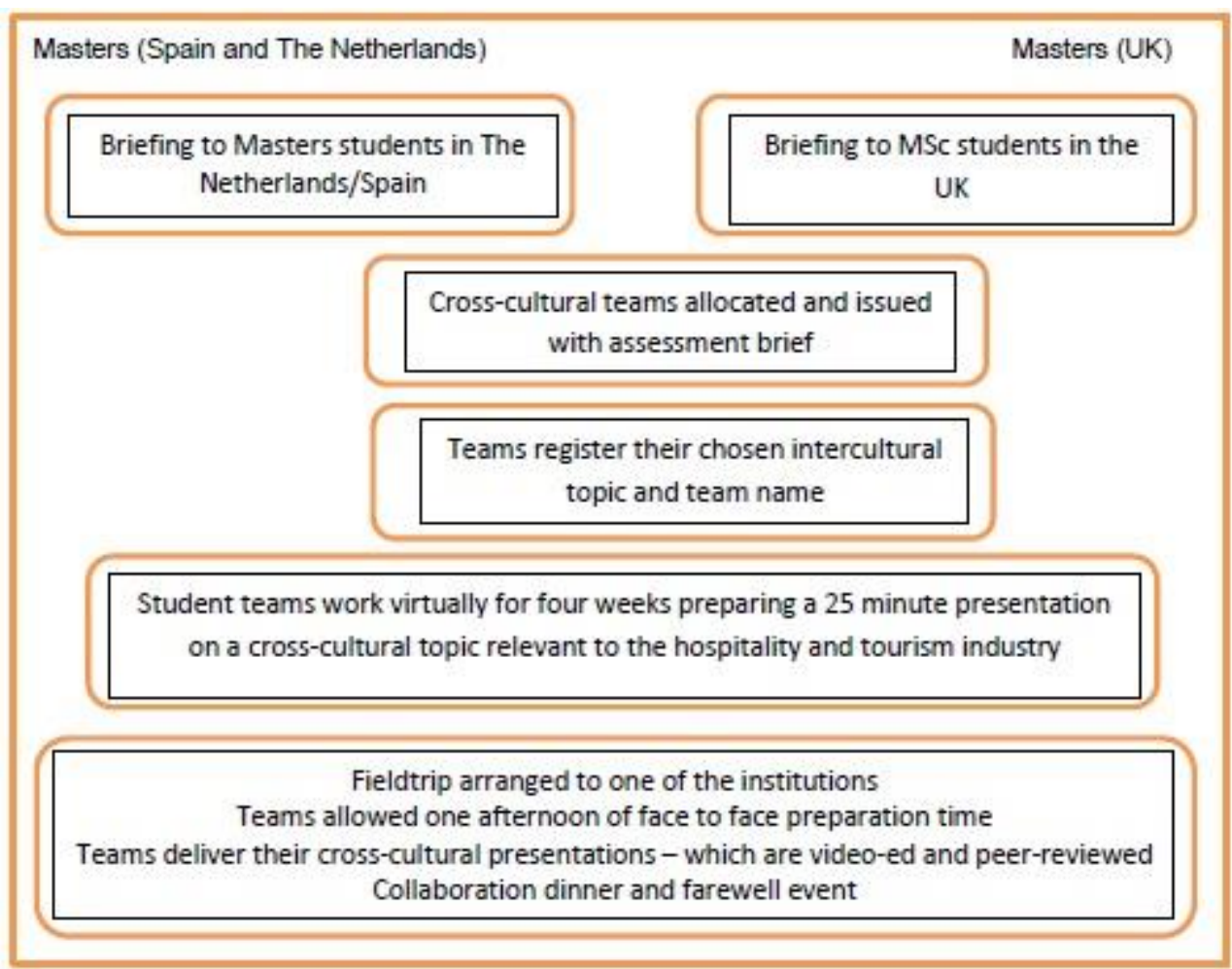

\section{Findings: Evaluating the virtual intercultural collaboration}

Early evaluations of the VIC initiative were undertaken as part of module evaluations separately in each institution of the postgraduate programmes concerned. This meant that there was no coherent overview. The design of the online survey aimed to identify participants' experiences of their skills in working virtually, interculturally and in teams, as well as specific features of the scheme alongside their overall appraisal of the VIC. The survey was developed by identifying specific items from other studies on virtual team working and intercultural competence (Sinicorpe, Norris \& Watanabe, 2012; Pazos, 2012; Olsen \& Olsen, 2012; Mortensen \& Hinds, 2001). All 69 participants on the VIC were invited by email to participate and a response rate of $32 \%$ was achieved (split evenly between students from the different institutions). Across the population 26 different nationalities were represented and the response rate covered 17 different nationalities. The nationalities of respondents included Chinese, German, British, Dutch, Spanish, Italian, Malaysian and Indian. Over $90 \%$ of respondents had lived and/or studied outside their home country highlighting the extent of international experience amongst respondents. There was a relatively narrow age range for the respondents, between 21-34 years of age though this reflects accurately on the typical age range for postgraduate students. There was a range of work experience identified amongst the group though one respondent had no work experience. Respondents were asked to include industry placements, part-time as well as full- time work in their calculations and two students identified over ten years' work experience though the overall average between 4 and 5 years. Predominantly this work experience had been in the hospitality, events and tourism industry. 


\subsection{Skills and experiences}

One of the first areas the academic team wanted to explore was students' perceptions of the benefits of virtual teams in the contemporary world of work. Respondents strongly agreed that the main benefits of virtual teams were opportunities to 'access global knowledge across organisations' $(94 \%)$, 'reduce business travel costs' $(94 \%)$, 'the ability to be in two places at once - physical and virtual presence' (94\%), and the ability 'have different people working on the same project at different times' $(90.6 \%)$. To a lesser extent respondents concurred that virtual teams provide opportunities to 'reduce carbon emissions' (69\%), 'reduced costs due to less individual burnout and jet lag' $(65 \%)$ and 'make improvements in workplace productivity' $(53 \%)$. These results indicate respondents query the extent to which virtual working approaches increase productivity and reduce organisation's carbon footprint while the wider business literature highlights the prospects virtual teams offer for workplace productivity and enhanced sustainable outcomes (Fisher \& Fisher, 2011; Pangil \& Chan, 2014). It is, however, worth considering whether the respondents in this study have yet to use technology which truly facilitates effective virtual working.

The respondents were also asked about different aspects of their skills as team members and then more specifically about the VIC experience itself. Table 1 represents the summary of set of questions, and responses.

Table 1. Postgraduate students views of team working and virtual team working

\begin{tabular}{|c|c|c|c|c|c|}
\hline Answer Options & $\begin{array}{l}\text { Strongly } \\
\text { Agree \% }\end{array}$ & $\underset{\%}{\operatorname{Agree}}$ & $\begin{array}{c}\text { Agree nor } \\
\text { Disagree } \\
\%\end{array}$ & $\begin{array}{l}\text { Disagree } \\
\%\end{array}$ & $\begin{array}{c}\text { Strongly } \\
\text { Disagree } \\
\%\end{array}$ \\
\hline i. I consider myself to be experienced at being a team member & 53.1 & 43.8 & 3.1 & $\mathbf{0}$ & $\mathbf{0}$ \\
\hline ii. My previous participation in teams has been successful & 43.8 & 53.1 & 3.1 & $\mathbf{0}$ & $\mathbf{0}$ \\
\hline iii. I felt unprepared for my role as a virtual team member & 3.1 & 12.5 & 18.8 & 46.8 & 18.8 \\
\hline iv. I have worked effectively in teams in an educational setting & 46.9 & 46.9 & 6.2 & $\mathbf{0}$ & $\mathbf{0}$ \\
\hline $\begin{array}{l}\text { v. I read material to understand how to be an effective virtual } \\
\text { team member }\end{array}$ & 12.5 & 34.4 & 28.1 & 12.5 & 12.5 \\
\hline vi. I have worked effectively in teams in a work setting & 40.7 & 53.1 & 6.2 & $\mathbf{0}$ & 0 \\
\hline $\begin{array}{l}\text { vii. I found it hard to engage in the virtual aspect of the } \\
\text { intercultural collaboration }\end{array}$ & 9.4 & 15.6 & 18.8 & 34.4 & 21.9 \\
\hline $\begin{array}{l}\text { viii. I don't feel the ability to participate as a virtual team } \\
\text { member is a useful career skill }\end{array}$ & 0 & 3.1 & 15.6 & 46.9 & 31.3 \\
\hline $\begin{array}{l}\text { ix. I found it easy to engage in the intercultural aspect of the } \\
\text { collaboration }\end{array}$ & 21.9 & 40.6 & 18.8 & 12.5 & 6.2 \\
\hline $\begin{array}{l}\text { x. I would recommend participating in the virtual team } \\
\text { collaboration }\end{array}$ & 28.1 & 40.6 & 18.8 & 9.4 & 3.1 \\
\hline $\begin{array}{l}\text { xi. I don't feel the ability to interact effectively with others from } \\
\text { different cultural backgrounds is a useful my career skill }\end{array}$ & 0 & 3.1 & 9.4 & 25 & 62.5 \\
\hline
\end{tabular}

The four questions (i, ii, iv and vi) all focused on participants' team working experiences and indicate that the respondents consider themselves to be veteran and effective team members. Responses related to the level of readiness for their VIC team member role (Question iii.) were more varied despite the detailed briefings aimed at preparing students for the scheme. Responses to item v. show that some respondents had sought out additional material on virtual team working to enhance their effectiveness while a quarter of all respondents agreed that they had found it hard to engage in the virtual aspect of the VIC. The majority of respondents would endorse participating in the VIC initiative (item x.) though there was a significant minority who would not recommend participation. Some insights into respondents' reluctance to endorse participation or why it was hard to engage in the virtual aspect of the scheme become clear in the open questions. Comments such as 'Had some problems getting the team together and it was difficult to share work!, 'Poor internet connection', 'The different schedules made it difficult to find suitable times to organise skype calls', as well as 'I was unable to participate in a few skype discussions as I had my part-time work to do however, I was well informed afterwards.' highlight the challenges of engaging in the virtual and international aspects of the collaboration. 
In relation to recommending participation in the VIC initiative responses varied from 'The students from the other place did not deliver any work', 'Miscommunication and low clarity on meeting deadlines before we met.' to 'the teamwork, the co-operation among one another, the proper division of presentation work amongst everyone, the efficient output.' and 'I got the chance to develop new communication skills as well as different ways to work virtually.' The students' responses to items viii and $x i$ suggest that they acknowledged that the ability to interact effectively with those from different cultural backgrounds and be a virtual team player would be important for their managerial careers. Overall these results suggest there appears to be a broadly affirmative view of participating on the VIC though the academic teams clearly need to reinforce the significance of the experience to students amidst the other demands of their programmes and future careers in the global hospitality and tourism industry (Avramenko, 2011; Suh, West \& Shin, 2012).

To enable the academic teams to gain some understanding of students' intercultural competence part of the survey included questions centred upon the Intercultural Development Inventory (IDI) (Sinicorpe et al., 2007). This inventory includes five or six stages, depending on the version of the inventory used, which chart developmental phases for intercultural competence. The first phase is denial with the subsequent phases labelled as; defence, minimisation, acceptance, adaptation and in some versions, integration, with the preliminary stages correlating with a lower level of intercultural competence where individuals are likely to deny and then defend themselves against cultural differences. Subsequent phases include efforts to limit exposure rather than engage with cultural differences. The later phases relate to the highest levels of intercultural competence signifying behaviours where there is acclimatisation to other cultures and finally there is the possibility of integration of own and different cultures. An abridged edition of the IDI, where eleven of the normal 50 items are used, was included in the online VIC survey. As would be expected with an international cohort of students with experience of living, working and studying abroad few respondents offered any replies associated with the lowest IDI levels of denial and defence. Where positive responses for the lowest of the IDI stages were evident the same respondents also gave positive responses for the higher intercultural competence levels of acceptance and adaptation. Overall this suggests respondents were capable of showing higher levels of intercultural competence with consistently strong responses for items including; 'I believe that verbal and non-verbal behaviour vary across cultures and that all forms of such behaviour are worthy of respect' and 'I have two or more cultural frames of reference and feeling positive about cultural differences'. While caution needs to be noted with these responses, due to the truncated nature of the IDI being used, there are indications that the respondents have a good level of intercultural competence due to their experiences of living, working and studying away from their home countries

\subsection{Experiences of the virtual intercultural collaboration}

A set of questions asked the VIC participants to state the media and the frequency of the different media used by their teams as part of the VIC. Facebook emerged as the overwhelming favourite amongst students with $75 \%$ of respondents identifying that they used it more than once a week. Skype and Email were typically used once a week or every two weeks, and the telephone was not used at all. Linkedln was mentioned by only one respondent, despite students being encouraged in the briefings to use this business-oriented social networking forum. Respondents indicated that they shared documents via Dropbox but no students used wikis, as had occurred in previous iterations of the initiative.

In research on virtual teams participation is typically explored via items where respondents are asked to imagine all the internal team communication and indicate the extent to which the communication media were used as proportions of $100 \%$ (Pazos, 2012; Olsen \& Olsen, 2012). In this study Facebook was used nearly $64 \%$ of the time whilst Skype and Email were utilized $21 \%$ and $15 \%$ respectively. These results reinforce the role of social media on this initiative and presents questions for how the academic teams might further encourage VIC participants to use more sophisticated and business-oriented media. However, these results may also reveal why respondents are cautious about the benefits and opportunities of virtual teams where they are reliant on familiar social media rather than those suited to focused business interactions. 
Intercultural virtual team performance was also included in the online survey using the questions developed by Mortensen \& Hinds (2001). This set of questions asked respondents to compare the very best team they have previously worked in, with their VIC team on a variety of dimensions, such as efficiency, quality, technical innovation, adherence to schedule work excellence and constructive communication. Table 2 summarises the responses emphasising that for a few participants the comparative performance of their VIC team was Excellent. A more significant proportion of respondents felt their VIC team's performance was good, specifically for the areas of quality, technical innovation, work excellence and constructive communication. Intercultural team performance was below average for a sizeable group of respondents specifically in the areas of efficiency, adherence to schedule and constructive communication. These results suggest that the VIC initiative is then providing a suitable learning experience of virtual team working where communication, efficiency and adherence to timescales are presenting challenges seen in the business world (Harvey et al., 2004; Fisher \& Fisher, 2011).

Table 2 Intercultural Team Performance

\begin{tabular}{|c|c|c|c|c|c|}
\hline Answer Options & $\begin{array}{c}\text { Poor } \\
\%\end{array}$ & $\begin{array}{l}\text { Fair } \\
\%\end{array}$ & $\begin{array}{c}\text { Average } \\
\%\end{array}$ & $\begin{array}{c}\text { Good } \\
\%\end{array}$ & $\begin{array}{c}\text { Excellent } \\
\%\end{array}$ \\
\hline Efficiency & 12.5 & 12.5 & 34.4 & 28.1 & 12.5 \\
\hline Quality & 9.4 & 9.4 & 31.3 & 37.4 & 12.5 \\
\hline Technical innovation & 6.3 & 3.1 & 34.4 & 40.6 & 15.6 \\
\hline Adherence to schedule & 15.6 & 12.5 & 34.4 & 15.6 & 21.9 \\
\hline Work excellence & 9.4 & $\mathbf{0}$ & 40.6 & 40.6 & 9.4 \\
\hline Constructive communication & 9.4 & 15.6 & 31.3 & 40.6 & 3.1 \\
\hline
\end{tabular}

Table 3 summarises students' responses to questions on their experiences on the VIC initiative and the extent to which their virtual, team and intercultural skills had been enhanced. The areas where respondents felt their abilities had developed significantly (either to a great extent or a moderate extent), in descending order included; 'the need to be people oriented when using technology', 'the ability to influence from a distance', 'enhanced an understanding of the limitations of technology', 'an ability to influence from a distance' and 'an ability to prepare for virtual meetings'. The majority of respondents felt their ability to use technology was not enhanced via the VIC initiative but this may be related to the reliance on familiar social media sites for VIC team communications. The table also indicates that the respondents felt the simulation only improved their 'ability to maintain virtual relationships' and 'work independently' to a low extent. This seems appropriate for postgraduate students who already feel they work effectively independently and due to the age range of the respondents they may be classed as 'digital natives' (Helsper \& Enyon, 2010).

Students were also asked to comment on their highlights and lowlights of the VIC initiative. The highlight remarks focused upon the opportunities presented in terms of 'meeting new team members', 'collaborating with people who don't follow the same classes and thus have different knowledge' and 'meeting new people that you did not know before and working towards a common goal with virtual tools'. There were also comments about the advantages of working with an even wider mix of nationalities and the chance to socialise and network as part of the scheme. The lowlight comments were more diverse although there were three comments about inconsistent weighting of assessment marks between the programmes, and there were comments that related more to specific issues. These included 'different teaching schedules making it difficult to coordinate Skype calls', 'imprecise instructions from teachers', 'a lack of interest in using other communication methods' and 'difficulties in clarifying things being done by team members'(Patterson et al., 2013). Overall these comments indicate that VIC participants recognise and experience the advantages and limitations of culturally diverse virtual team working. Moreover, the organisation of the student team work across different cultural mind-sets and time zones, are the same challenges experienced by those in the wider world of work (Patterson et al., 2013; Crossman \& Bordia, 2011; Fisher \& Fisher, 2011; Olsen \& Olsen, 2012; Richards \& Bilgin, 2012). 


\section{p.18-27. DOI https://doi.org/10.1016/j.ijme.2016.01.002.}

Table 3 Experiences of the VIC

\begin{tabular}{|c|c|c|c|c|}
\hline Answer Options & $\begin{array}{l}\text { A Great } \\
\text { extent } \\
\%\end{array}$ & $\begin{array}{l}\text { A } \\
\text { Moderate } \\
\text { extent \% }\end{array}$ & $\begin{array}{l}\text { A Low } \\
\text { extent } \\
\%\end{array}$ & $\begin{array}{l}\text { Not at } \\
\text { all } \\
\%\end{array}$ \\
\hline i. Improved your ability to use technology & 6.3 & 37.5 & 15.6 & 40.6 \\
\hline $\begin{array}{l}\text { ii. Enhanced your understanding of the value of communicating via } \\
\text { technology }\end{array}$ & 31.3 & 43.8 & 21.9 & 3 \\
\hline $\begin{array}{l}\text { iii. Improved your ability to contribute via } \\
\text { skype/audio/video conference }\end{array}$ & 18.8 & 40.6 & 21.8 & 18.8 \\
\hline iv. Improved your ability to influence from a distance & 31.3 & 50 & 18.7 & 0 \\
\hline v. Helped you understand your learning style preferences & 40.7 & 31.3 & 21.9 & 3.1 \\
\hline vi. Identified the need to be people oriented when using technology & 34.3 & 53.1 & 9.4 & 3 \\
\hline vii. Improved your ability to start up virtual relationships & 40.7 & 34.3 & 12.5 & 12.5 \\
\hline $\begin{array}{l}\text { viii. Identified how your learning style preferences impact on your } \\
\text { approach to undertaking tasks }\end{array}$ & 31.3 & 43.7 & 18.8 & 6.2 \\
\hline ix. Improved your ability to maintain virtual relationships & 21.9 & 25 & 46.9 & 6.2 \\
\hline x. Improved your ability to team work & 25 & 40.7 & 28.1 & 6.2 \\
\hline xi. Improved your ability to work independently & 15.6 & 37.5 & 31.3 & 9.4 \\
\hline xii. Enhanced your self-awareness of the impact you have on others & 34.3 & 37.5 & 25 & 0 \\
\hline xiii. Enhanced your ability to prep for virtual meetings & 21.9 & 59.3 & 6.3 & 12.5 \\
\hline xiv. Enhanced your ability to manage virtual meetings & 25 & 53.1 & 12.5 & 9.4 \\
\hline $\begin{array}{l}\text { xv. Provided more insights into the challenges of } \\
\text { working across cultures }\end{array}$ & 43.7 & 31.3 & 15.6 & 9.4 \\
\hline xvi. Enhanced your understanding of the limitations of technology & 50 & 31.3 & 15.5 & 6.3 \\
\hline
\end{tabular}

Participants were also asked to comment on the improvements which should be made by the faculty team for subsequent versions of the VIC. Improvements suggested included; 'giving the same information to all students', 'giving the same briefings to both sets of students', 'providing equal weightings for the assessments in both programmes' and 'encouraging students to communicate frequently'. It is clear from these comments that students were not aware that exactly the same briefings were given to the programmes by the same members of staff who travelled between the institutions purposively to ensure consistency. The results highlight that students from different programmes and institutions may interpret instructions differently due to the settings and educational contexts which they are familiar with (Patterson et al., 2013; Crossman \& Bordia, 2011). This is despite faculty members from across the three institutions agreeing content and format for these sessions. One aspect of these comments highlights a persistent issue which the VIC scheme has faced over assessment loading for the group presentation element. The weighting given to the presentation differs by $5 \%$ between the programmes and institutions. This is due to variations in credit ratings and expectations of proportional assessment between the programmes and policies on group work in the educational institutions based in three different countries. Therefore achieving complete consistency has proved elusive, though the faculty teams continue to explore more options to achieve exact parity, and continue to emphasise that the other component of module assessment associated with their participation on the initiative emphasises the need for them to reflect on the process of virtual, intercultural learning (Cotton et al., 2013).

\section{Discussion and analysis}

The results of this survey identify that the VIC teaching and learning initiative across the postgraduate programmes operating in the three European locations provides students with the chance to experience virtual, intercultural and team work through learning interventions. The advantages of the scheme are apparent where students engage with fellow postgraduate students studying the same area of vocational and professional management studying in different cultural contexts. That the programmes draw from different international markets for students further diversifies the cultural mix, and alongside the geographical dispersion a suitable simulation for team 
working emerges (Pangil \& Chan, 2014; Au \& Marks, 2012). Other methods of enhancing postgraduate students' intercultural experiences and competencies would normally involve greater resource investment (time and money) and possible immersion abroad. It is widely recognised by the participating Faculty that their postgraduate student cohorts tend to have had some international experience but the evidence from the VIC is that the initiative extends this further and incorporates the virtual dimension too. Research on virtual working in business reinforces the results from the survey regarding the prevalence of specific media highlighting the efficacy of the activity (Pazos, 2012; Olsen \& Olsen, 2012). By providing a safe experience of the challenges of intercultural, team and virtual working students, who are about to join an international industry, can draw upon their skills and learning when they move into the workplace as recommended more widely in experiential learning approaches (Tiwari et al., 2014, Ruhanen, 2005). Comments from alumni at graduation ceremonies have reinforced these arguments where the VIC experience has been recognised as a unique part of these postgraduates' student experiences.

The survey responses suggest respondents see themselves as relatively intercultural competent though further scrutiny is imperative here given the limitations of the abbreviated questions used (Egan \& Bendick, 2008). The digital literacy skills of students also deserve to be questioned given the reliance on 'social media' sites as the primary form for team communication. Ostensibly as 'digital natives' the respondents (and the wider student group) are clearly confident with technology but it could be that the technology used by the students in this initiative does not meet the standards or protocols associated with the business world and formal work settings. The academic teams are currently investigating ways to encourage wider adoption of other communication technologies for the initiative but without dictating media which may disadvantage specific users.

The academic teams also experienced challenges in securing support for the initiative over the long term given the time and money associated with coordinating, managing preparing and delivering the VIC (Patterson et al., 2013). Such an initiative may be recognised by students and Faculty as an innovative teaching and learning development but evidence over the longer term is difficult to capture. Addressing the questions of parity across programmes with different rules on credit allocation and assessment, despite suggestions of convergence across European HEls, offers the academic teams with an additional set of challenges, even where the actual differences are marginal. Continued demand for management postgraduates with combinations of intercultural, team and virtual working skills and knowledge (Richards \& Bilgin, 2012; Erez et al., 2013; Taras et al., 2013) suggests, however, that the argument for maintaining such teaching and learning innovations based on experiential learning is well-grounded.

\section{Conclusions and recommendations}

Using experiential learning in this way to mimic the workplace offers substantial opportunities for students to develop relevant knowledge and skills. Working virtually and interculturally presents challenges to individuals and organisations in the world of work and this initiative provides to some level an authentic experience which may enhance, to a greater or lesser extent students' intercultural competence and virtual and team working skills. However, it is only through collaboration between competing educational institutions that such an initiative can create a true replication of an intercultural experience specifically in terms of geographical dispersion and virtual working. The results from the survey indicate though that managing parity across programmes and universities can be challenging and effective coordination and management requires that resources are adequately allocated (Patterson et al., 2013). A particular area of concern from the survey involves ensuring students engage with suitable technology for their virtual collaborative interactions.

In addition faculty need to be acutely familiar with the administrative systems within which they operate, and be prepared to discuss explicitly the likely challenges of coordination and delivery of such initiatives with their partner institutions. Agreeing to and maintaining a schedule of virtual and face to face meetings between partner institution faculty and relevant administrators is also essential to ensure the achievement of the desired student learning experiences (Patterson et al., 2013). Allaying student concerns about their capacity to participate and equity across institutions also means that faculty need to demonstrate they have acted upon previous cohorts' feedback on the scheme (Crossman \& Bordia, 2011). The authors have made use of previous students' insights and 
networking between alumni and current students to identify improvements and the value of the collaboration. The limitations of this study clearly emanate from the fact that the data is based on one case of a virtual intercultural collaboration initiative. There appear, however, to be very few such schemes in place. When developing the initial idea the team did search for examples and cases of best practice, but at the time these were difficult to identify. The academic team hope that their future research will include longitudinal results for future incarnations of the VIC itself but also wider engagement with and sharing of their experiences of this teaching and learning development with other interested parties.

\section{References}

Analoui, B., Sambrook, S., Doloriert, C. (2014). Engaging students in group work to maximise tacit knowledge sharing and use. The International Journal of Management Education, 12: 35-43.

Au, Y. \& Marks, A. (2012). Virtual teams are literally and metaphorically invisible. Forging identity in culturally diverse virtual teams. Employee Relations, 34(3): 271-287.

Avramenko, A. (2011). Enhancing students' employability through business simulation. Education + Training, 54(5): 355-367.

Baker, C.A. Jensen, P. J. Kolb, D. A. (2002) Conversational learning: an experiential approach to knowledge creation. Westpoint: Quorum books

Barron, P. (2014). International issues in curriculum design and delivery in tourism and hospitality education. The Routledge Handbook of Tourism and Hospitality Education, 181.

Bigelow, B., Elsass, P., Arndt, M. (2015). Dialogue in the graduate management classroom: Learning from diversity. The International Journal of Management Education, 13: 48-56.

Blasco, M. (2009). Cultural Pragmatists? Student Perspectives on Learning Culture at a Business School. Academy of Management Learning and Education, 8(2): 174-187.

Cotton, D. R., George, R., \& Joyner, M. (2013). Interaction and influence in culturally mixed groups. Innovations in Education and Teaching International,50(3), 272-283.

Crossman, J., \& Bordia, S. (2011). Friendship and relationships in virtual and intercultural learning: internationalising the business curriculum. Australian Journal of Adult Learning, 51(2), 329.

De Jong, R., Schalk, R. \& Curseu, P.L. (2008). Virtual communicating, conflicts and performance in teams, Team Performance Management. Academy of Management Learning and Education 14 (7/8): 364-380.

De Vita, G. (2002) 'Cultural Equivalence in the Assessment of Home and International Business Management Students: A UK Exploratory study' Studies in Higher Education, 27(2): 221- 231

De Vita, G. (2001) 'Learning Styles, Culture and Inclusive Instruction in the Multicultural Classroom: A Business and Management Perspective' Innovations in Education and Teaching International, 38(2): 165-174

Duncan, T., Scott, D.G. \& Baum, T. (2013). The mobilities of hospitality work: an exploration of issues and debates. Annals of Tourism Research, 41 (1): 1-19.

Edelheim, J. \& Ueda, D. (2007). Effective use of simulation in Hospitality Management Education - a Case Study. Journal of Hospitality, Leisure, Sport \& Tourism Education, 6(1): 18-28.

Egan, M., \& Bendick, M. (2008). Combining Multicultural Management and Diversity into One Course on Cultural Competence. Academy of Management Learning and Education, 7(3): 387-393. 
Erez, M., Lisak, A., Harush, R., Glikson, E., Nouri, R., Shokef, E. (2013). Going Global: Developing Management Students' Cultural Intelligence and Global Identity in Culturally Diverse Virtual Teams. Academy of Management Learning and Education, 12(3): 330-355.

Finch, D., Peacock, M., Lazdowski, D., Hwang, M. (2015). Managing emotions: A case study exploring the relationship between experiential learning, emotions and student performance. The International Journal of Management Education, 13(1): 23-36.

Fisher, K. \& Fisher, M. (2011). Managers Guide to Virtual Teams. McGrawHill, New York.

Gannon, J. (2008). Developing Intercultural Skills for International Industries: The Role of Industry and Educators, Hospitality, Leisure, Sport and Tourism Network: Enhancing Series: Internationalisation (2008): 1-18.

Harvey, M., Novicevic, M., Garrison, G. (2004). Challenges to staffing global virtual teams. Human Resource Management Review, 14: 275-294.

Helsper, E. J., \& Eynon, R. (2010). Digital natives: where is the evidence? British educational research journal, 36(3), 503-520.

Hertel, G. Geister, G. \& Kontradt, U. (2005). Managing virtual teams: A review of current empirical research. Human Resource Management Review, 15: 69-95.

Hodari, D. \& Sturman, M.C. (2014). Who's in Charge Now? The Decision Autonomy of Hotel General Managers. Cornell Hospitality Quarterly, 55(4): 433-447.

Mumford, A., \& Honey, P. (1992). Questions and answers on learning styles questionnaire. Industrial and Commercial Training, 24(7).

Huddleston, P., \& Unwin, L. (2007). Teaching and learning in further education: diversity and change. Oxford, Routledge.

Joy, S., \& Poonamallee, L. (2013). Cross-Cultural Teaching in Globalized Management Classrooms: Time to Move From Functionalist to Postcolonial Approaches?. Academy of Management Learning and Education, 12(3): 396-413.

Keeling, R. (2006). The Bologna Process and the Lisbon Research Agenda: the European Commission's expanding role in higher education discourse. European Journal of Education, 41(2), 203-223.

Kolb, A. Y, \& Kolb, D.A., (2005) Learning styles and learning spaces: enhancing experiential learning in higher education. Academy of Management learning and education, 4: 193-212

Lee, S. A. (2008). Increasing student learning: A comparison of students' perceptions of learning in the classroom environment and their industry based experiential learning assignments. Journal of Teaching in Travel \& Tourism, 7(4), 37-54.

Lipnack, J. \& Stamps, J. (2000). Virtual teams: People working across boundaries with technology ( 2nd ed.) New York: John Wiley and Sons.

Maier, T., \& Thomas, N. (2013). Hospitality Leadership Course Design and Delivery: A BlendedExperiential Learning Model. Journal of Hospitality \& Tourism Education, 25: 11- 21.

Matveev, A. \& Milter, R. (2004). The value of intercultural competence for performance of multicultural teams. Team Performance Management, 10(5/6): 104-111.

Matveev, A. V., \& Nelson, P. E. (2004). Cross cultural communication competence and multicultural team performance perceptions of American and Russian managers. International Journal of Cross Cultural Management, 4(2), 253-270.

Mendenhall, M., Arnardottir, A., Oddou, G., Burke, L. (2013). Developing Cross-Cultural Competencies in Management Education via Cognitive-Behaviour Therapy. Academy of Management Learning and Education, 12(3): 436-451. 
Mintzberg, H. \& Gosling, J. (2002). Educating Managers Beyond Borders. Academy of Management Learning and Education, 1(1): 64-76.

Morris, S. (2008) Virtual Team working: making it happen. Industrial and Commercial Training, 40(3): 129-133.

Mortensen, M. \& Hinds, P.J. (2001). Conflict and shared identity in geographically distributed teams, international. Journal of Conflict Management, 12(3): $212-238$.

Newman, F., Couturier, L., \& Scurry, J. (2010). The future of higher education: Rhetoric, reality, and the risks of the market. John Wiley \& Sons.

Olsen J. \& Olsen, L. (2012). Virtual team trust: task, communication and sequence. Team Performance Management, 18(5/6): 256-276.

Pangil, F. \& Chan, J.M. (2014) The mediating effect of knowledge sharing on the relationship between trust and virtual team effectiveness. Journal of Knowledge Management, 18(1): 92-106.

Piercy, N., \& Caldwell, N. (2011). Experiential learning in the international classroom: Supporting learning effectiveness and integration. The international journal of management education, 9(2), 2536.

Patterson, L., Carrillo, P. B., \& Salinas, R. S. (2011). Lessons from a global learning virtual classroom. Journal of Studies in International Education, May, 16(2): 182-197.

Pazos, P. (2012) Conflict management and effectiveness in virtual teams. Team Performance Management, 18(7/8): 401-417.

Pless, N. M., Maak, T., \& Stahl, G. K. (2011). Developing responsible global leaders through international service-learning programs: The Ulysses experience. Academy of Management Learning \& Education, 10(2), 237-260.

Pless, N. \& Maak, T. (2012). Promoting corporate social responsibility and sustainable development through management development: what can be learned from international service learning programs?. Human Resource Management, 51 (6).

Richards, D \& Bilgin, A. (2012). Cross-cultural study into ICT student attitudes and behaviours concerning teams and project work. Multicultural Education \& Technology Journal, 6(1): 18-35.

Ruhanen, L. (2005). Bridging the divide between theory and practice: Experiential learning approaches for tourism and hospitality management education. Journal of Teaching in Travel \& Tourism, 5(4), 35-39.

Sinicrope, C. Norris, J. \& Watanabe, Y. (2012) Understanding and assessing intercultural Competence: a summary of theory, research, and Practice (technical report for the foreign language Program evaluation project) available at: http://www.hawaii.edu/sls/uhwpesl/26(1)/Norris.pdf

Suh, E., West, J.J. \& Shin, J. (2012). Important competency requirements for managers in the hospitality industry. Journal of Hospitality, Leisure, Sport and Tourism Education, 11; 101- 112

Taras, V., Caprar, D., Rotting, D., Sarala, R., Zakaria, N., Zhao, F., Jiménez, A., Wankel, C., Lei, W., Minor, M., Bryla, P., Ordeñana, X., Bode, A., Schuster, A., Vaiginiene, E., Froese, F., Bathula, H.,

Yajnik, N., Baldegger, R. \& Huang, V. (2013). A Global Classroom? Evaluating the effectiveness of Global Virtual Collaboration as a Teaching Tool in Management Education. Academy of Management Learning and Education, 12(3): 414-435.

Tavitiyaman, P. Weerakit, N. Ryan, B. (2014). Leadership Competencies for Hotel General Managers: The Differences in Age, Education, and Hotel Characteristics. International Journal of Hospitality \& Tourism Administration, 15 (2):191-126.

Tiwari, S. R., Nafees, L., \& Krishnan, O. (2014). Simulation as a pedagogical tool: 
Gannon, Judith, M.; Rodrigo, Zaida; Santomà, Ricard. Learning to work interculturally and virtually: developing postgraduate hospitality management students across International HE institutions. The International Journal of Management Education, 2016. Volume 14, issue 1 (March), p.18-27. DOI https://doi.org/10.1016/j.ijme.2016.01.002.

Vygotsky, L. (1978). Interaction between learning and development. Readings on the development of children, 23(3), 34-41.

Warwick, P. (2014). The international business of higher education - A managerial perspective on the internationalisation of UK universities. The International Journal of Management Education, 12(1): 91 103.

Woods, P., Barker, M., \& Hibbins, R. (2011). Tapping the benefits of multicultural group work: An exploratory study of postgraduate management students. The International Journal of Management Education, 9(2), 59-70.

Xiao, Q. O'Neill, J.W. \& Mattila, A.S. (2012). The role of hotel owners: the influence of corporate strategies on hotel performance. International Journal of Contemporary Hospitality Management, 24 (1) $122-139$ 